\title{
DJ-1 is activated in medulloblastoma and is associated with cell proliferation and differentiation
}

\author{
Jia-ping Lin ${ }^{1 \dagger}$, Bin-cai Pan ${ }^{2 \dagger}$, Bin $\mathrm{Li}^{3}$, Yang $\mathrm{Li}^{3}$, Xiao-ying Tian ${ }^{4}$ and $Z \mathrm{Zhi}_{\mathrm{Li}}{ }^{*}$
}

\begin{abstract}
Background: DJ-1 is a key regulator in human tumorigenesis, including brain malignancies. The mechanisms by which DJ-1 contributes to the pathogenesis of medulloblastoma (MB) remain unclear, and its impact on the prognosis for patients with MB has not been identified. The aim of this study was to determine whether the DJ-1 protein is associated with tumorigenesis of MBs, and whether DJ-1 is a valuable factor for predicting the prognosis of patients with MB.

Methods: We collected 66 pairs of MB and adjacent normal cerebellum samples. Expression of DJ-1, Ser ${ }^{473}$-phosphorylated-Akt (p-Akt), PTEN, and Ki-67 (MIB-1) was detected by immunohistochemical staining, and the correlation of these immunostaining results with the clinicopathological features of patients with MB was determined.
\end{abstract}

Results: High DJ-1 expression (48.5\%, 32/66) in tumor cells of MBs was significantly associated with the classic MB variant $(P=0.003)$, high proliferative activity $(P=0.002)$ and undifferentiated tumor $(P=0.001)$, whereas high p-Akt expression $(56.1 \%, 37 / 66)$ was associated with tumor metastasis stage $(P=0.007)$, undifferentiated tumor $(P=0.007)$, and high-risk tumor $(P=0.002)$. High $D J-1$ expression also correlated with high $p$-Akt expression and high MIB-1 index. However, only high levels of DJ-1 $(P=0.009)$ and high MIB-1 index $(P=0.001)$ were strong independent prognostic factors associated with worse overall survival.

Conclusions: Although the validity of the preliminary data in this study needs to be confirmed by a larger number of cases, our study indicates that DJ-1, PTEN, and p-Akt might play important roles in cell proliferation and differentiation of MBs. The evaluation of expression of DJ-1 and related proteins might be useful for predicting the prognosis of patients with MB.

Keywords: Medulloblastoma, DJ-1, PI3K/Akt pathway, PTEN, Prognosis

\section{Background}

Medulloblastoma (MB) is the most common malignant tumor of central nervous system in children [1], while it rarely occurs in adults [2]. Although multimodality treatment regimens, including surgery, radiotherapy (RT), and chemotherapy, have greatly improved disease outcome, about one-third of patients with MB remain incurable. Moreover, the 5 -year disease survival rate is only $36 \%$ for patients with $\mathrm{MB}$ with tumor dissemination and recurrence $[3,4]$. The accumulated studies in $\mathrm{MB}$ have come to a consensus that $\mathrm{MB}$ can be classified into four core

\footnotetext{
*Correspondence: lizhi@mail.sysu.edu.cn

${ }^{\dagger}$ Equal contributors

${ }^{3}$ Department of Pathology, The First Affiliated Hospital, Sun Yat-sen

University, 58, Zhongshan Road II, Guangzhou 510080, China

Full list of author information is available at the end of the article
}

subgroups: WNT (Wingless), SHH (Sonic hedgehog), Group 3, and Group 4 [5]. Each of these subtypes has a distinct molecular profile and genomic defects, which are associated with varied clinical parameters and patient outcomes. However, despite extensive investigation, the mechanism underlying $\mathrm{MB}$ progression has not been fully elucidated. More precise prognostic predictors and more effective therapies for MBs are therefore required.

Recently, research evidence has suggested that DJ-1 plays a role in human tumorigenesis. DJ-1 is a 189 amino acid protein, and was originally identified as an oncogene that, in combination with H-RAS, can transform mouse NIH3T3 cells [6]. The DJ-1 protein has been found in various malignant tumor cells, including prostate cancer, non-small cell lung cancer, laryngeal cancer, 
ovarian carcinoma, and cervical cancer, where it plays a role in increasing cell proliferation and metastasis [7-10]. However, the effect of DJ-1 on the development and progression of MB has not yet been investigated.

DJ-1 is considered to contribute to oncogenesis by upregulating protein kinase $\mathrm{B}(\mathrm{PKB} / \mathrm{Akt})$-mediated cell survival $[6,11]$. Akt is a $57-\mathrm{kDa}$ serine/threonine kinase, and is a central mediator involved in the signal transduction of various growth-controlling pathways that involve phosphatidylinositol 3'-kinase (PI3K). PI3K, activated by growth factors, catalyzes the phosphorylation of phosphatidylinositol $(4,5)$-biphosphate (PIP2) to phosphatidylinositol $(3,4,5)$-triphosphate (PIP3). PIP3 in turn recruits 3-phosphoinositide-dependent kinase (PDK), which phosphorylates and activates Akt [12]. Phosphorylated Akt (p-Akt) plays a key role in multiple signaling pathways, including cell proliferation, apoptosis, and transcription [13]. Basic research has demonstrated that DJ-1 could antagonize the tumor suppressor PTEN to inhibit the activity of the PTEN gene and finally promote the proliferation of tumor cells [11]. PTEN is a key negative regulator of the PI3Kprotein kinase B signaling pathway. In MBs, loss of heterozygosity of chromosome $10 \mathrm{q}$ is frequent at the position where PTEN is located (10q23.31) [14,15]. Dysregulation of PTEN was found to contribute to overactivation of the PI3K/Akt signaling pathway [16,17]. Thus, we hypothesized that DJ-1 might contribute to the progression of $\mathrm{MB}$ by regulating the PTEN and Akt pathways. However, we could not find any report about the relationship between DJ-1 and tumorigenesis of MBs, or the mechanisms involved.

In this study, we first examined the DJ-1, PTEN, and p-Akt expression in surgical MB tissue specimens and paired tumor-adjacent tissue specimens. The aim of this study was to determine whether the DJ-1 protein is associated with tumorigenesis of MBs, and if it would be a valuable factor for predicting the prognosis of patients with $\mathrm{MB}$.

\section{Methods}

\section{Patients and clinical management}

In retrospective study, we examined 66 pairs of paraffin wax-embedded $\mathrm{MB}$ and adjacent normal cerebellum samples collected from the Pathology Department of the First Affiliated Hospital of Sun Yat-sen University and Tongjiang Hospital of Guangdong during the period of 2003 to 2012. None of the patients had received chemotherapy or RT before surgical treatment. All experimental protocols were carried out with the approval of the Committee on Use of Human \& Animal Subjects in Teaching and Research of Sun Yat-sen University, according to the Helsinki Declaration.

All patients had undergone midline suboccipital craniectomy to resect the tumor completely or partially. Extent of resection was defined on the basis of surgical reports and/or postoperative images. Patients received different treatment protocols after surgery, based on age stratification. All patients under 3 years of age received chemotherapy after surgery with standard regimens consisting of six course of temozolomide, vincristine, and cisplatin. Patients aged over 3 years initially received RT. Postoperative RT was conducted using craniospinal irradiation (CSI), with a subsequent boost to the posterior fossa. Patients received a total dose ranging from 40 to 54 Gy. After RT, six courses of standard chemotherapy with temozolomide, vincristine, and cisplatin were also used for these patients. Imaging inspection was repeated at intervals of 3 to 6 months to evaluate treatment response, metastasis, and tumor recurrence. All 66 patients were given a follow-up investigation, and follow-up was terminated in March 2013.

\section{Histopathological subtype}

All the samples were re-evaluated according to the criteria of the WHO classification [18] by two experienced pathologists, with differences resolved by careful discussion. Of the 66 case of MB, 50 (75.7\%) were classified as classic MB, $14(21.2 \%)$ as the desmoplastic variant, $1(1.5 \%)$ as the large cell/anaplastic variant, and 1 as MB with myogenic differentiation (previously termed medullomyoblastoma).

\section{Immunohistochemical staining and scoring}

Serial sections $4 \mu \mathrm{m}$ thick were cut from eah tissue block and mounted on aminopropyltriethoxysilane (APES)-coated glass slides. After routine preparation of slides, the sections were incubated with one of the following antibodies: rabbit anti-human monoclonal PTEN antibody (1:100 dilution; D4.3), p-Akt (Ser 473) rabbit monoclonal antibody (1:25; D9E) (both Cell Signaling technology, MA, USA), rabbit anti-human polyclonal DJ-1 antibody (1:100; FL-189; Santa Cruz Biotechnology, SantaCruz, CA, USA), or Ki-67 (1:100 dilution; MIB-1; Dako Co., Glostrup, Denmark) for $60 \mathrm{~min}$, respectively. Slides were processed using a ChemMate Envision/horseradish peroxidase kit (Dako) for $30 \mathrm{~min}$ at room temperature, followed by development with diaminobenzidine (DAB) for visualization. Positive controls consisted of biopsies of prostate tissue containing carcinoma and normal parenchyma (for DJ-1 and PTEN) and breast cancer (p-Akt). Negative controls were prepared by substituting nonimmune serum for primary antibodies.

Immunohistochemical staining evaluation was conducted as described previously [19]. Scoring of the percentage of immunoreactive tumor cells was as follows: $0(0 \%), 1$ (1 to $10 \%), 2$ (11 to $50 \%)$, and 3 (>50\%). The staining intensity was visually scored and stratified as 0 (negative), 1 (weak), 2 (moderate), and 3 (strong). A final immunoreactivity score was obtained for each case by multiplying the percentage and the intensity score. The median score was 4.5. Thus, 
DJ-1, PTEN, and p-Akt protein expression levels were further classified as lower (when the score was less than 4.5) and higher (when it was greater than 4.5). In order to reduce variation, all immunohistochemical staining was separately evaluated and scored semiquantitatively by two pathologists without knowledge of the clinical data of patients. The final score for protein expression in each case was the mean of the scores given by the two observers.

The proliferative activity of tumor cells was evaluated by counting the Ki-67 (MIB-1) labeling index with image analysis (Olympus Cell D1; Soft Imaging System GmbH, Munster, Germany) counting at least 1000 tumor cells at high magnification ( $\times 40$ objective) in fields with the largest number of positive cells. Tissues were considered to have a high MIB-1 index (MI) when the Ki-67 labeling value was greater than the mean Ki-67 labeling value of all $66 \mathrm{MBs}$.

\section{Statistical analysis}

Statistical analysis was performed using SPSS software (version 14.0 for Windows; SPSS Inc., Chicago, IL, USA). Qualitative data are presented as number and percent. The $\chi^{2}$ was used for comparison between groups, and $P<0.05$ was considered significant. Overall survival (OS) was counted (months) from the date of diagnosis to the date of death or last follow-up before study closure. Kaplan-Meier method and Cox regression were used for survival analysis.

\section{Ethics committee approval and patient consent}

This study was approved by Sun Yat-sen University review board or ethics committee.

\section{Results and discussion}

\section{DJ-1, p-Akt, and PTEN expression in MBs}

All $66 \mathrm{MB}$ samples showed detectable levels of DJ-1 and p-Akt in tumor cells with variations in positive percentage and intensity (Figure 1). However, DJ-1 and p-Akt expression was not present in adjacent normal cerebellar tissue. The areas with high DJ-1 expression were observed to almost overlap with those with p-Akt high expression. Proliferative activity was particularly prominent in areas with high expression of DJ-1 or p-Akt, which were $8.5 \%$
(32/66) and 56.1\% (37/66), respectively. In the desmoplastic variant MBs, DJ-1 and p-Akt showed a staining pattern, in which the internodular (undifferentiated or poorly differentiated) areas had higher expression than the intranodular (neuronal differentiated) regions (Figure 2a, b). PTEN expression was observed in normal cerebellum, including the molecular layer and inner granule cell layer. However, PTEN protein level was significantly decreased in tumor cells, and low expression of PTEN was seen in all MB samples. We found that $84.8 \%(56 / 66)$ of samples, including all the classic MBs and four of the desmoplastic variant samples, showed no detectable or only weak levels of PTEN in tumor cells. A focal immunopositive PTEN signal was observed in the intranodular regions of the other 10 desmoplastic variant MBs (Figure 2c). In addition, the areas with high expression of p-Akt coincided with the regions with loss of PTEN expression.

\section{Correlation of DJ-1, p-Akt, and PTEN expression with the clinicopathological characteristics of medulloblastoma}

We found statistically significant correlations of high DJ-1 protein expression with slightly older children and adults. Although MB is the most common in children, it rarely occurs in adults. In this study, several adult patients were collected and stratified into the study group of patient more than 3 years old. $(P=0.030)$, classic variant MBs $(P=0.003)$, high proliferative activity $(P=0.002)$, undifferentiated tumor $(P=0.001)$, and high-risk tumor $(P=0.031)$. High $\mathrm{p}$-Akt expression was also associated with tumor metastatic stage $(P=0.007)$, undifferentiated tumor $(P=0.007)$, and high-risk tumor $(P=0.002)$. High p-Akt expression also correlated with high DJ-1 expression in tumor cells $(P=0.010)$. However, the expression levels of these proteins were not statistically associated with sex, tumor location, or size of residual tumor (Table 1).

\section{Prognostic relevance of DJ-1 and p-Akt expression in MBs} The follow-up time for the 66 patients with MB was 2-59 months. The most recent follow-up showed that 40 patients were still alive, and the 5-year OS was approximately $60.6 \%$. Kaplan-Meier survival analysis revealed that patients with $\mathrm{MB}$ with high DJ-1 expression had poorer OS than those

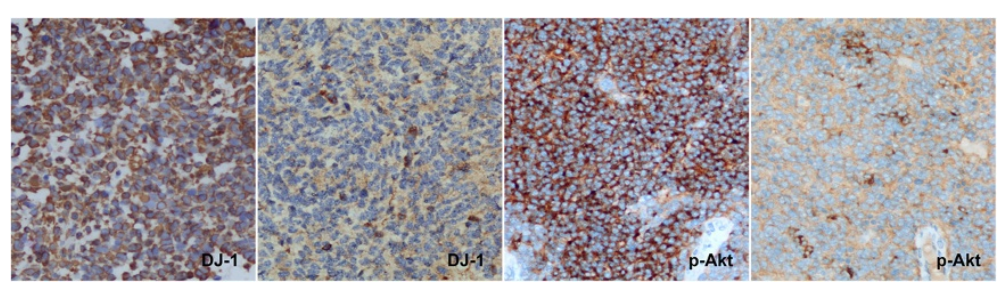

Figure 1 Expression levels of DJ-1 and p-Akt in tumor cells with varying levels of positive percentage and intensity. High and low expression of DJ-1 are shown on the left side, and high and low expression of p-Akt on the right side. (Original magnification $\times 400$ ). 


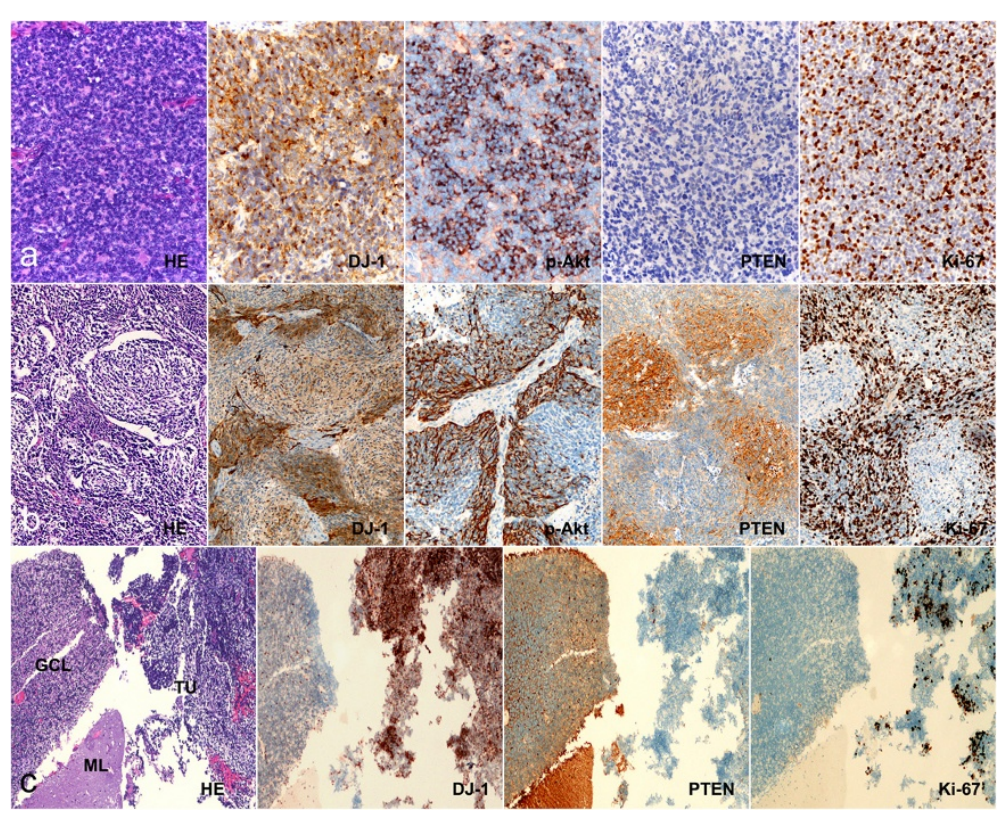

Figure 2 Immunohistochemical analysis of DJ-1, PTEN, p-Akt, and Ki-67 expressionin MBs. (a) In classic MBs, DJ-1 and p-Akt appeared to have diffused positive signal in tumor cells, but PTEN was negative in most cases. Proliferative activity (Ki-67 labeling) was particularly prominent in areas with high expression of DJ-1 and p-Akt. (b) In desmoplastic MBs, high expression of DJ-1, p-Akt, and Ki-67 was observed in internodular areas with undifferentiated or poorly differentiated tumor cells; however, detectable signals of PTEN were observed in intranodular areas with neuronal differentiation. (c) Immunohistochemical analysis showed that expression of DJ-1 was significantly higher in tumor cells than in normal cerebellum, but PTEN was found to be expressed at significantly lower levels in tumor cells compared with adjacent normal cerebellum. ML, molecular layer of cerebellum; GCL, granule cell layer of cerebellum; TU, tumor. (Original magnification × 200).

with low DJ-1 expression $(P=0.007)$. Patients with MB tumors with high MI also had poorer prognosis than those with low MI $(P=0.001)$ (Figure 3). Univariate analyses of each factor with Cox log-rank analysis (Table 2) showed that the other clinicopathological parameters, including metastatic stage, histopathological subtype, and cell differentiation were not significantly associated with tumor prognosis. In multivariate analysis (Table 3 ), only high proliferative activity $(P=0.001)$ and high DJ-1 expression $(P=0.009)$ in tumor were independent predictors of OS for patients with MB.

MBs are a heterogenous group of highly malignant embryonal brain tumors [20]. For many years, MBs have been stratified into high-risk and standard-risk groups according to age, metastatic stage at diagnosis, and extent of surgical resection. Standard-risk patients are those diagnosed at ages over 3 years, have no metastases at presentation, and have manageable residual tumor $\left(<1.5 \mathrm{~cm}^{2}\right)$ after surgery. High-risk patients are those do not fulfill these criteria [21], and these patients should receive more intensive treatment. A recent study has shown that the combination of chemotherapy and RT has improved the 5-year survival rate, which is now 55\% to $76 \%$ for high-risk patients and $70 \%$ to $80 \%$ for standardrisk patients [22]. However, in the present study, we found that there was no significant difference in OS of patients with different tumor risk, and tumor risk stratification was not an independent factor for predicting the prognosis of patients with MB. The different treatment protocols based on age stratification did not show any marked benefit for prognosis. These results indicate that risk-adapted treatments are not entirely suitable for all patients with $\mathrm{MB}$. Hence, it is important to identify novel clinical and biological factors that can be used to predict treatment response and accurately select patients who may benefit from a more or less aggressive treatment, and to improve risk stratification.

The importance of DJ-1 in the progression of MBs has not been identified, although recent studies have demonstrated that the DJ-1 molecule is relevant to the various human tumors [20,23-25]. In the human brain, DJ-1 has been observed in neurons [26] and non-neural cells [27]. DJ-1 has also been associated with autosomal recessive early-onset parkinsonism, with loss of function of DJ-1 leading to neurodegeneration [28]. In gliomas, the relationship between high DJ-1 expression and high-grade glioma has indicated that DJ-1 might play a role in the acceleration of glioma progression [20]. In the current study, we found the first evidence that high DJ-1 expression was closely correlated with undifferentiated tumor and active proliferation of tumors. Survival analysis revealed that high DJ-1 expression was significantly associated with low OS in patients with MB. Moreover, on multivariate analysis, high DJ-1 expression emerged as an independent factor influencing the prognosis of patients 
Table 1 Correlation between proteins expression and clinicopathological characteristics of patients with MB

\begin{tabular}{|c|c|c|c|c|c|}
\hline \multirow{2}{*}{$\begin{array}{l}\text { Clinicopathological } \\
\text { characteristics }\end{array}$} & \multicolumn{2}{|c|}{ DJ-1 expression ${ }^{a}$} & \multicolumn{2}{|c|}{ p-Akt expression ${ }^{a}$} & \multirow{2}{*}{$\begin{array}{l}\text { Proliferative activit) } \\
\text { (Ki-67 value) })^{\mathrm{b}}\end{array}$} \\
\hline & Low $(n=34)$ & High $(n=32)$ & Low $(n=29)$ & High $(n=37)$ & \\
\hline \multicolumn{6}{|l|}{ Age, year } \\
\hline$\leq 3(n=19)$ & 13 & 6 & 7 & 12 & $25.28 \pm 7.59$ \\
\hline$>3(n=47)$ & 21 & 26 & 22 & 25 & $26.77 \pm 8.74$ \\
\hline$P$ value & 0.030 & & 0.275 & & 0.519 \\
\hline \multicolumn{6}{|l|}{ Sex } \\
\hline Male $(n=43)$ & 23 & 20 & 18 & 25 & $25.80 \pm 7.31$ \\
\hline Female $(n=23)$ & 11 & 12 & 11 & 12 & $27.36 \pm 10.23$ \\
\hline$P$ value & 0.619 & & 0.527 & & 0.475 \\
\hline \multicolumn{6}{|l|}{ WHO histological subtype ${ }^{c}$} \\
\hline Classic $(n=50)$ & 23 & 27 & 22 & 28 & $25.17 \pm 7.75$ \\
\hline Desmoplastic $(n=14)$ & 11 & 3 & 7 & 7 & $30.03 \pm 9.89$ \\
\hline$P$ value & 0.003 & & 0.536 & & 0.055 \\
\hline \multicolumn{6}{|l|}{ Tumor location } \\
\hline Fourth ventricle $(n=29)$ & 16 & 13 & 10 & 19 & $26.65 \pm 8.51$ \\
\hline Outside fourth ventricle $(n=37)$ & 18 & 19 & 19 & 18 & $26.11 \pm 8.42$ \\
\hline$P$ value & 0.556 & & 0.065 & & 0.795 \\
\hline \multicolumn{6}{|l|}{ Residual tumor size } \\
\hline$\leq 1.5 \mathrm{~cm}^{2}(\mathrm{n}=54)$ & 29 & 25 & 24 & 30 & $25.75 \pm 8.14$ \\
\hline$>1.5 \mathrm{~cm}^{2}(\mathrm{n}=12)$ & 5 & 7 & 5 & 7 & $29.04 \pm 9.38$ \\
\hline$P$ value & 0.221 & & 0.829 & & 0.222 \\
\hline \multicolumn{6}{|l|}{ Metastatic status } \\
\hline $\mathrm{MO}(\mathrm{n}=12)$ & 5 & 7 & 3 & 9 & $28.20 \pm 7.39$ \\
\hline M1 $(n=54)$ & 29 & 25 & 26 & 28 & $25.93 \pm 8.61$ \\
\hline$P$ value & 0.221 & & 0.007 & & 0.401 \\
\hline \multicolumn{6}{|l|}{ Tumor risk } \\
\hline Standard $(n=6)$ & 2 & 4 & 1 & 5 & $30.50 \pm 9.58$ \\
\hline High $(n=60)$ & 32 & 28 & 28 & 32 & $25.93 \pm 8.25$ \\
\hline$P$ value & 0.031 & & 0.010 & & 0.201 \\
\hline \multicolumn{6}{|l|}{ Differentiation level } \\
\hline Undifferentiated $(n=39)$ & 14 & 25 & 13 & 26 & $27.28 \pm 8.82$ \\
\hline Differentiated $(n=27)$ & 20 & 7 & 16 & 11 & $25.00 \pm 7.71$ \\
\hline$P$ value & 0.001 & & 0.007 & & 0.281 \\
\hline \multicolumn{6}{|l|}{ DJ-1 expression } \\
\hline Low $(n=34)$ & & & 20 & 14 & $23.33 \pm 6.22$ \\
\hline High $(n=32)$ & & & 9 & 23 & $29.54 \pm 9.28$ \\
\hline$P$ value & & & 0.001 & & 0.002 \\
\hline \multicolumn{6}{|l|}{ p-Akt expression } \\
\hline Low $(n=29)$ & 20 & 9 & & & $25.13 \pm 6.92$ \\
\hline High $(n=37)$ & 14 & 23 & & & $27.29 \pm 9.38$ \\
\hline$P$ value & 0.001 & & & & 0.303 \\
\hline
\end{tabular}

${ }^{a} x^{2}$ test.

'One-way ANOVA.

'We did not carry out statistical analysis for the large cell/anaplastic variant and medullomyoblastoma because there were insufficient numbers of cases. 

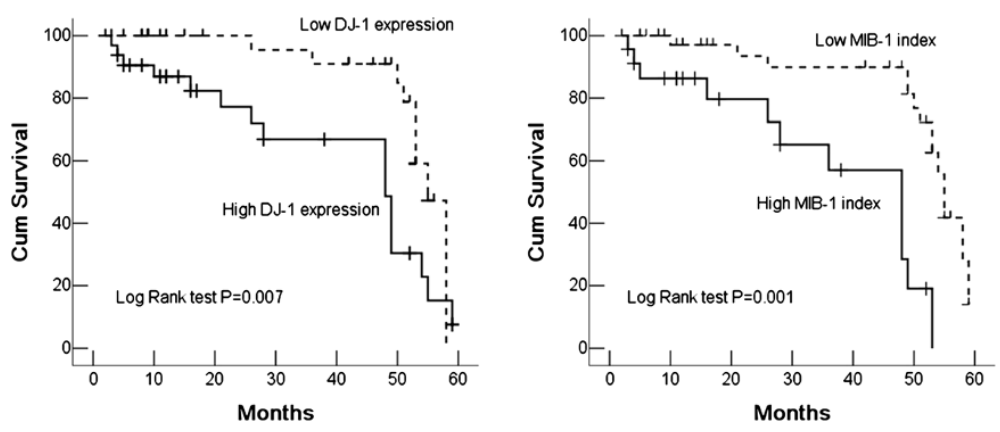

Figure 3 Kaplan-Meier survival curves for DJ-1 expression and proliferative activity in tumor cells of MBs. Patients with MB with high DJ-1 expression (left) or high MIB-1 index (right) had poorer OS.

with MB. These results indicate that DJ-1 may promote tumor progression and could be an independent prognostic factor by influencing cell proliferation and differentiation. To date, there is still no conclusive evidence that measures of cell proliferation have clinical utility, and the relevant studies have provided conflicting data. Some studies have shown an association between a simple evaluation of mitotic count and survival for children with MB [29,30]; however, survival analyses do not support the use of the Ki-67/MIB-1 index as prognostic indicator [31], although high bromodeoxyuridine ( $\mathrm{BrdU})$ index $(>20 \%)$ appeared to indicated worse prognosis in one study [32]. In the present study, high MIB-1 index had a strong correlation with poor prognosis of patients with $\mathrm{MB}$ and may be an independent indicator of tumor. More importantly, high proliferative activity of tumor cells was associated with high expression of DJ-1 protein. These data suggest that the cell proliferation influencing the prognosis of patients with $\mathrm{MB}$ might be modulated, at least partly, by the pathway involving the DJ-1 molecule.

DJ-1 is considered to contribute to oncogenesis by upregulating $\mathrm{PKB} / \mathrm{Akt}-\mathrm{mediated}$ cell survival $[6,11]$. However, in this study, however, we did not find an association between high p-Akt expression by tumor and high MIB-1 index of tumor cells, although high p-Akt expression was observed to correlate closely with tumor differentiation and metastasis.

Consistent with this result, p-Akt expression was not a prognostic indicator for predicting the prognosis of patients with MB. On the one hand, activated Akt was expressed at much higher levels in MB tumors compared with normal human cerebellum, indicating that p-Akt may be up-regulated in tumourigenesis and tumor progression of MBs, such as modulating tumor differentiation and promoting metastasis. On the other hand, activated Akt is an essential, but not the only, pathway in promoting cell proliferation of MBs.

In addition, in the current study, we found that the areas having high DJ-1 expression always overlapped with those having p-Akt high expression.
These results suggest that DJ-1 does indeed have a role in modulating the Akt pathway in MBs, but it might not be the only factor to influence activated Akt in tumor progression. Recent studies have demonstrated that several growth factor receptors involving the PI3K/Akt cascade in their signal transduction are expressed in $\mathrm{MB}$, such as the insulin-like growth factor-I receptor, Tropomyosin-related kinase B (TrkB), Platelet-derived growth factor receptorbeta (PDGFRB), and c-Kit [33-35]. PI3K/Akt signaling has also been found to enhance the effects of Hedgehog in MB tumor cells and their cerebellar precursors [36,37]. However, in the present study we did not detect co-expression of DJ-1 and p-Akt in the same tumor cell, which would have provided more direct evidence to elucidate their relationship and cooperative effect on the modulation of tumor progression. The precise mechanism of DJ-1, p-Akt, and related growth factor receptors in the development and progression of MBs will be investigated in further studies.

PTEN is another key negative regulator of the PI3K signaling pathway [38]. As MBs are known to display allelic losses of chromosomal region 10q, where the PTEN tumor suppressor gene is located, we hypothesize that inactivation of PTEN could constitute a possible mechanism that might be responsible for Akt activation. Recent data showed that losses of 10q are associated with metastatic disease at diagnosis [39], and the PTEN mutation detected in another study occurred only in a recurrent tumor that also carried a p53 mutation [40]. It seems that the frequency of PTEN mutations is low in MBs, and that mutation may be associated with a more aggressive or relapsing phenotype of the tumor. In the present study, we did not examine mutations of the PTEN gene. However, we found that PTEN was inactivated at the protein expression level. PTEN was significantly decreased in MB tumor cells compared with normal human cerebellum, indicating that inactivation of PTEN at the transcriptional level may also be involved in the regulation of PTEN and thus may influence the activation of Akt. Epigenetic inactivation of PTEN has recently been reported in 
Table 2 Kaplan-Meier analysis for OS rate of patients with MB

\begin{tabular}{|c|c|c|c|}
\hline $\begin{array}{l}\text { Clinicopathological } \\
\text { characteristics }\end{array}$ & $\begin{array}{l}\text { Mean survival } \\
\text { time, months }\end{array}$ & $95 \% \mathrm{Cl}$, months & $P$ value $^{a}$ \\
\hline \multicolumn{4}{|l|}{ Age, year } \\
\hline$\leq 3$ & $44.96 \pm 5.18$ & 34.81 to 55.12 & 0.495 \\
\hline$>3$ & $47.72 \pm 2.72$ & 42.95 to 52.48 & \\
\hline \multicolumn{4}{|l|}{ Sex } \\
\hline Male & $47.16 \pm 2.70$ & 41.86 to 52.46 & 0.880 \\
\hline Female & $46.60 \pm 4.10$ & 38.56 to 54.64 & \\
\hline \multicolumn{4}{|l|}{$\begin{array}{l}\text { WHO histological } \\
\text { subtype }^{\text {b }}\end{array}$} \\
\hline Classic & $48.39 \pm 2.41$ & 43.66 to 53.12 & 0.263 \\
\hline Desmoplastic & $41.39 \pm 5.93$ & 29.76 to 53.02 & \\
\hline \multicolumn{4}{|l|}{ Tumor location } \\
\hline Fourth ventricle & $46.35 \pm 3.84$ & 38.82 to 53.88 & 0.889 \\
\hline Outside fourth ventricle & $47.66 \pm 2.61$ & 42.44 to 52.87 & \\
\hline \multicolumn{4}{|l|}{ Residual tumor size } \\
\hline$\leq 1.5 \mathrm{~cm}^{2}$ & $37.78 \pm 6.14$ & 25.73 to 45.83 & 0.052 \\
\hline$>1.5 \mathrm{~cm}^{2}$ & $49.68 \pm 2.28$ & 45.19 to 54.16 & \\
\hline \multicolumn{4}{|l|}{ Metastatic status } \\
\hline MO & $42.08 \pm 7.92$ & 26.54 to 57.62 & 0.971 \\
\hline M1 & $47.45 \pm 2.33$ & 42.87 to 52.02 & \\
\hline \multicolumn{4}{|l|}{ Tumor risk } \\
\hline Standard & $46.64 \pm 2.34$ & 41.04 to51.24 & 0.062 \\
\hline High & $23.75 \pm 5.20$ & 13.54 to33.95 & \\
\hline \multicolumn{4}{|l|}{ Differentiation level } \\
\hline Undifferentiated & $46.84 \pm 3.03$ & 40.89 to 52.79 & 0.823 \\
\hline Differentiated & $46.87 \pm 3.52$ & 39.96 to 53.78 & \\
\hline \multicolumn{4}{|l|}{ DJ-1 expression } \\
\hline Low & $53.29 \pm 1.79$ & 49.77 to 56.81 & 0.007 \\
\hline High & $40.28 \pm 3.79$ & 32.84 to 47.71 & \\
\hline \multicolumn{4}{|l|}{ p-Akt expression } \\
\hline Low & $47.76 \pm 3.19$ & 41.50 to 54.03 & 0.663 \\
\hline High & $46.30 \pm 3.23$ & 39.97 to 52.63 & \\
\hline
\end{tabular}

aLog rank test.

${ }^{b}$ We did not carry out statistical analysis for the large cell/anaplastic variant and medullomyoblastoma because there were insufficient numbers of cases.

several human tumors, including central nervous system tumors [41], but the related mechanisms of PTEN inactivation at the mRNA transcription level need to be clarified in further investigations.

In the current study, we found that high DJ-1 expression was closely associated with classic MBs, and the areas with high expression of DJ-1or p-Akt always coincided with the regions that had loss of PTEN expression. These regions were usually undifferentiated areas of classic MBs or internodular areas of desmoplastic MBs. However, expression of DJ-1 and p-Akt was decreased in
Table 3 Cox regression model for multivariate analyses of prognostic factor in MBs

\begin{tabular}{|c|c|c|c|}
\hline Variable & $\begin{array}{l}\text { Hazard } \\
\text { ratio }\end{array}$ & $\begin{array}{l}95 \% \text { confidence } \\
\text { interval }\end{array}$ & $P$ value \\
\hline Age ( $\leq 3$ years versus $>3$ years) & 0.396 & 0.140 to 1.118 & 0.080 \\
\hline Gender (male versus female) & 1.421 & 0.485 to 4.160 & 0.521 \\
\hline $\begin{array}{l}\text { WHO histological subtype } \\
\text { (classic versus desmoplastic) }\end{array}$ & 0.931 & 0.308 to 2.808 & 0.899 \\
\hline $\begin{array}{l}\text { Tumor location (fourth ventricle } \\
\text { versus outside fourth ventricle) }\end{array}$ & 1.201 & 0.404 to 3.573 & 0.741 \\
\hline $\begin{array}{l}\text { Residual tumor size }\left(\leq 1.5 \mathrm{~cm}^{2}\right. \\
\left.\text { versus }>1.5 \mathrm{~cm}^{2}\right)\end{array}$ & 0.391 & 0.139 to 1.102 & 0.075 \\
\hline Metastatic status ( $M_{0}$ versus $M_{1}$ ) & 1.720 & 0.310 to 9.546 & 0.534 \\
\hline Tumor risk (standard versus high) & 0.695 & 0.041 to 11.92 & 0.802 \\
\hline $\begin{array}{l}\text { Differentiation (differentiated } \\
\text { versus undifferentiated) }\end{array}$ & 0.348 & 0.121 to 0.998 & 0.050 \\
\hline MIB-1 index (low versus high) & 5.949 & 1.986 to 17.814 & 0.001 \\
\hline DJ-1 expression (low versus high) & 4.531 & 1.443 to 14.223 & 0.009 \\
\hline p-Akt expression (low versus high) & 0.765 & 0.217 to 2.698 & 0.678 \\
\hline
\end{tabular}

intranodular areas of desmoplastic MBs, in which the tumor cells appeared to have varying degrees of neuronal differentiation. PTEN expression was also detectable in regions with neuronal differentiation. Therefore, we hypothesize that DJ-1and PTEN could modulate tumor cell differentiation via Akt pathway. DJ-1 is due to its effects on the PI3K signaling pathway, and may modulate PTEN function to produce hyperphosphorylation of Akt $[6,11]$. Recent data have shown that PI3K/Akt signaling enhances the effects of Hedgehog in MBs and their cerebellar precursors, and that it may represent an indispensable precondition for the molecular realization of the Hedgehog signal [36,37]. Inhibiting Hedgehog-dependent gene expression in $\mathrm{MB}$ can cause cell cycle arrest, consistent with the initiation of neuronal differentiation and loss of neuronal stem cell-like characteristics [42]. Molecular analysis has identified that the desmoplastic variant of MB is associated with activation of the Hedgehog-Patched signaling pathway [43]. The desmoplastic variant has been associated with a better prognosis than classic MB in some studies, although there is no significant difference in outcome for these two variants in our study. Thus, the DJ-1/PTEN/ p-Akt/Hedgehog signaling system might play important roles in modulating cell differentiation and further influence the outcome of MBs. Thus, blocking cell growth and inducing cell differentiation in MBs by interfering with the DJ-1 protein and Hedgehog pathway might represent a novel approach to treat this tumor. In fact, some inhibitors of the Hedgehog pathway, such as cyclopamine and HhAntag, have been proven to cause the regression of murine tumor allografts in vivo, and induce rapid death of cells from freshly resected human MBs $[44,45]$. 


\section{Conclusion}

Although the precise roles of DJ-1, PTEN and p-Akt in MBs have not been identified, our study indicates links between these molecules in their protein expression level in MBs, and the validity of preliminary data in this study needs to be confirmed by a larger number of cases. We consider that DJ-1, PTEN, and p-Akt might play important roles in cell proliferation and differentiation of MBs, and their expression levels might be useful parameters for predicting the prognosis of patients with MB. Of course, more rigorous investigations are necessary to clarify their intrinsic links.

\section{Competing interests}

The authors declare that they have no competing interests.

\section{Authors' contributions}

JPL and BCP made contributions to acquisition of clinical data, and analysis of the histological features by H\&E staining and immunoassays, and drafted the manuscript. $B L$ and $Y L$ carries on the immunohistochemical staining. XYT carried out statistical analysis. ZL revised manuscript critically for important intellectual content and had given final approval of the version to be published. All authors read and approved the final manuscript.

\section{Acknowledgement}

This study was supported by Scientific Research Project of Guangdong Provincial Science and Technology (grant numbers 2010B060900104 and 2012A030400008).

\section{Author details \\ ${ }^{1}$ Department of Neurosurgery, the First Affiliated Hospital, Sun Yat-sen University, 58, Zhongshan Road II, Guangzhou 510080, China. ${ }^{2}$ Department of Pathology, Tongjiang Hospital of Guangdong, Nanguo Road East, Shunde District, Foshan 528300, China. ${ }^{3}$ Department of Pathology, The First Affiliated Hospital, Sun Yat-sen University, 58, Zhongshan Road II, Guangzhou 510080, China. ${ }^{4}$ School of Chinese Medicine, Hong Kong Baptist University, 7, Baptist University Road, Kowloon Tong, Hong Kong, China.}

Received: 4 June 2014 Accepted: 18 November 2014

Published: 5 December 2014

\section{References}

1. Stevens MC, Cameron AH, Muir KR, Parkes SE, Reid H, Whitwell H: Descriptive epidemiology of primary central nervous system tumours in children: a population-based study. Clin Oncol (R Coll Radiol) 1991, 3:323-329.

2. Louis DN, Ohgaki H, Wiestler OD, Cavenee WK, Burger PC, Jouvet A, Scheithauer BW, Kleihues P: The 2007 WHO classification of tumours of the central nervous system. Acta Neuropathol 2007, 114:97-109.

3. Gajjar A, Chintagumpala M, Ashley D, Kellie S, Kun LE, Merchant TE, Woo S, Wheeler G, Ahern V, Krasin MJ, Fouladi M, Broniscer A, Krance R, Hale GA, Stewart CF, Dauser R, Sanford RA, Fuller C, Lau C, Boyett JM, Wallace D, Gilbertson RJ: Risk-adapted craniospinal radiotherapy followed by high-dose chemotherapy and stem-cell rescue in children with newly diagnosed medulloblastoma (St Jude Medulloblastoma-96): long-term results from a prospective, multicentre trial. Lancet Oncol 2006, 7:813-820.

4. Packer RJ, Gajjar A, Vezina G, Rorke-Adams L, Burger PC, Robertson PL, Bayer L, LaFond D, Donahue BR, Marymont MH, Muraszko K, Langston J, Sposto R: Phase III study of craniospinal radiation therapy followed by adjuvant chemotherapy for newly diagnosed average-risk medulloblastoma. J Clin Oncol 2006, 24:4202-4208.

5. Kool M, Korshunov A, Remke M, Jones DT, Schlanstein M, Northcott PA, Cho YJ, Koster J, Schouten-van Meeteren A, van Vuurden D, Clifford SC, Pietsch T, von Bueren AO, Rutkowski S, McCabe M, Collins VP, Bäcklund ML, Haberler C, Bourdeaut F, Delattre O, Doz F, Ellison DW, Gilbertson RJ, Pomeroy SL, Taylor MD, Lichter P, Pfister SM: Molecular subgroups of medulloblastoma: an international meta-analysis of transcriptome, genetic aberrations, and clinical data of WNT, SHH, Group 3, and Group 4 medulloblastomas. Acta Neuropathol 2012, 123:473-484.

6. Nagakubo D, Taira T, Kitaura H, Ikeda M, Tamai K, Iguchi-Ariga SM, Ariga H: DJ-1, a novel oncogene which transforms mouse NIH3T3 cells in cooperation with ras. Biochem Biophys Res Commun 1997, 231:509-513.

7. Hod Y: Differential control of apoptosis by DJ-1 in prostate benign and cancer cells. J Cell Biochem 2004, 92:1221-1233.

8. Bai J, Guo C, Sun W, Li M, Meng X, Yu Y, Jin Y, Tong D, Geng J, Huang Q, Qi J, Fu S: DJ-1 may contribute to metastasis of non-small cell lung cancer. Mol Biol Rep 2012, 39:2697-2703.

9. Zhu XL, Wang ZF, Lei WB, Zhuang HW, Jiang HY, Wen WP: DJ-1: a novel independent prognostic marker for survival in glottic squamous cell carcinoma. Cancer Sci 2010, 101:1320-1325.

10. Davidson B, Hadar R, Schlossberg A, Sternlicht T, Slipicevic A, Skrede M, Risberg B, Flørenes VA, Kopolovic J, Reich R: Expression and clinical role of DJ-1, a negative regulator of PTEN, in ovarian carcinoma. Hum Pathol 2008, 39:87-95.

11. Kim RH, Peters M, Jang Y, Shi W, Pintilie M, Fletcher GC, DeLuca C, Liepa J, Zhou L, Snow B, Binari RC, Manoukian AS, Bray MR, Liu FF, Tsao MS, Mak TW DJ-1, a novel regulator of the tumor suppressor PTEN. Cancer Cell 2005, 7:263-273.

12. Alessi DR, James SR, Downes CP, Holmes AB, Gaffney PR, Reese CB, Cohen P: Characterization of a 3-phosphoinositide-dependent protein kinase which phosphorylates and activates protein kinase Balpha. Curr Bio/ 1997, 7:261-269.

13. Song G, Ouyang G, Bao S: The activation of Akt/PKB signaling pathway and cell survival. J Cell Mol Med 2005, 9:59-71.

14. Bigner SH, Mark J, Friedman HS, Biegel JA, Bigner DD: Structural chromosomal abnormalities in human medulloblastoma. Cancer Genet Cytogenet 1988, 30:91-101.

15. Griffin CA, Hawkins AL, Packer RJ, Rorke LB, Emanuel BS: Chromosome abnormalities in pediatric brain tumors. Cancer Res 1988, 48:175-180

16. Chow LM, Baker SJ: PTEN function in normal and neoplastic growth. Cancer Lett 2006, 241:184-196.

17. Hartmann W, Digon-Söntgerath B, Koch A, Waha A, Endl E, Dani I, Denkhaus D, Goodyer CG, Sörensen N, Wiestler OD, Pietsch T: Phosphatidylinositol 3'-kinase/AKT signaling is activated in medulloblastoma cell proliferation and is associated with reduced expression of PTEN. Clin Cancer Res 2006, 12:3019-3027.

18. Louis DN, Ohgaki H, Wiestler OD: WHO Classification of Tumours of the Central Nervous System. Lyon: IARC press; 2007.

19. Wang C, Fang M, Zhang M, Li W, Guan H, Sun Y, Xie S, Zhong X: The positive correlation between DJ-1 and $\beta$-catenin expression shows prognostic value for patients with glioma. Neuropathology 2013, 33:628-636.

20. Varan A: Risk-adapted chemotherapy in childhood medulloblastoma. Expert Rev Anticancer Ther 2001, 11:771-780.

21. Ellison DW, Clifford SC, Gajjar A, Gilbertson RJ: What's new in neuro-oncology? Recent advances in medulloblastoma. Eur J Paediatr Neurol 2003, 7:53-66.

22. Gilbertson RJ: Medulloblastoma: signaling a change in treatment. Lancet Oncol 2004, 5:209-218.

23. Hinkle DA, Mullett SJ, Gabris BE, Hamilton RL: DJ-1 expression in glioblastomas shows positive correlation with p53 expression and negative correlation with epidermal growth factor receptor amplification. Neuropathology 2011, 31:29-37.

24. Pei XJ, Wu TT, Li B, Tian X, Li Z, Yang QX: Increased expression of macrophage migration inhibitory factor and DJ-1 contribute to cell invasion and metastasis of nasopharyngeal carcinoma. Int J Med Sci 2013, 11:106-115.

25. Li Y, Cui J, Zhang CH, Yang DJ, Chen JH, Zan WH, Li B, Li Z, He YL: Highexpression of DJ-1 and loss of PTEN associated with tumor metastasis and correlated with poor prognosis of gastric carcinoma. Int J Med Sci 2013, 10:1689-1697.

26. Rizzu P, Hinkle DA, Zhukareva V, Bonifati V, Severijnen LA, Martinez D, Ravid R, Kamphorst W, Eberwine JH, Lee VM, Trojanowski JQ, Heutink P: DJ-1 colocalizes with tau inclusions: a link between parkinsonism and dementia. Ann Neurol 2004, 55:113-118

27. Bandopadhyay R, Kingsbury AE, Cookson MR, Reid AR, Evans IM, Hope AD, Pittman AM, Lashley T, Canet-Aviles R, Miller DW, McLendon C, Strand C, Leonard AJ, Abou-Sleiman PM, Healy DG, Ariga H, Wood NW, de Silva R, Revesz T, Hardy JA, Lees AJ: The expression of DJ-1 (PARK7) in normal human CNS and idiopathic Parkinson's disease. Brain 2004, 127:420-430. 
28. Bonifati V, Rizzu P, van Baren MJ, Schaap O, Breedveld GJ, Krieger E, Dekker MC, Squitieri F, Ibanez $\mathrm{P}$, Joosse $\mathrm{M}$, van Dongen JW, Vanacore $\mathrm{N}$, van Swieten JC, Brice A, Meco G, van Duijn CM, Oostra BA, Heutink P: Mutations in the DJ-1 gene associated with autosomal recessive early-onset parkinsonism. Science 2003, 299:256-259.

29. Gilbertson RJ, Jaros E, Perry RH, Kelly PJ, Lunec J, Pearson AD: Mitotic percentage index: a new prognostic factor for childhood medulloblastoma. Eur J Cancer 1997, 33:609-615.

30. McManamy CS, Lamont JM, Taylor RE, Cole M, Pearson AD, Clifford SC, Ellison DW: United Kingdom Children's Cancer Study Group: Morphophenotypic variation predicts clinical behavior in childhood non-desmoplastic medulloblastomas. J Neuropathol Exp Neurol 2003, 62:627-632.

31. Ohta T, Watanabe T, Katayama Y, Kurihara J, Yoshino A, Nishimoto H, Kishimoto H: TrkA expression is associated with an elevated level of apoptosis in classic medulloblastomas. Neuropathology 2006, 26:170-177.

32. Ito S, Hoshino T, Prados MD, Edwards MS: Cell kinetics of medulloblastomas. Cancer 1992, 70:671-678.

33. Wang JY, Del Valle L, Gordon J, Rubini M, Romano G, Croul S, Peruzzi F, Khalili K, Reiss K: Activation of the IGF-IR system contributes to malignant growth of human and mouse medulloblastomas. Oncogene 2001, 20:3857-3868.

34. MacDonald TJ, Brown KM, LaFleur B, Peterson K, Lawlor C, Chen Y, Packer RJ, Cogen P, Stephan DA: Expression profiling of medulloblastoma: PDGFRA and the RAS/MAPK pathway as therapeutic targets for metastatic disease. Nat Genet 2001, 29:143-152

35. Chilton-Macneill S, Ho M, Hawkins C, Gassas A, Zielenska M, Baruchel S: C-kit expression and mutational analysis in medulloblastoma. Pediatr Dev Pathol 2004, 7:493-498.

36. Klein RS, Rubin JB, Gibson HD, DeHaan EN, Alvarez-Hernandez X, Segal RA, Luster AD: SDF-1 alpha induces chemotaxis and enhances Sonic hedgehog-induced proliferation of cerebellar granule cells. Development 2001, 128:1971-1981.

37. Rubin JB, Kung AL, Klein RS, Chan JA, Sun Y, Schmidt K, Kieran MW, Luster AD, Segal RA: A small-molecule antagonist of CXCR4 inhibits intracranial growth of primary brain tumors. Proc Natl Acad Sci U S A 2003, 100:13513-13518.

38. Martelli AM, Cocco L, Capitani S, Miscia S, Papa S, Manzoli FA: Nuclear phosphatidylinositol 3, 4, 5-trisphosphate, phosphatidylinositol 3-kinase, Akt, and PTen: emerging key regulators of anti-apoptotic signaling and carcinogenesis. Eur J Histochem 2007, 51:125-131.

39. Reardon DA, Michalkiewicz E, Boyett JM, Sublett JE, Entrekin RE, Ragsdale ST, Valentine MB, Behm FG, Li H, Heideman RL, Kun LE, Shapiro DN, Look AT: Extensive genomic abnormalities in childhood medulloblastoma by comparative genomic hybridization. Cancer Res 1997, 57:4042-4027.

40. Rasheed BK, Stenzel TT, McLendon RE, Parsons R, Friedman AH, Friedman HS, Bigner DD, Bigner SH: PTEN gene mutations are seen in high-grade but not in low-grade gliomas. Cancer Res 1997, 57:4187-4190.

41. Baeza N, Weller M, Yonekawa Y, Kleihues P, Ohgaki H: PTEN methylation and expression in glioblastomas. Acta Neuropathol 2003, 106:479-485.

42. Berman DM, Karhadkar SS, Hallahan AR, Pritchard Jl, Eberhart CG, Watkins DN, Chen JK, Cooper MK, Taipale J, Olson JM, Beachy PA: Medulloblastoma growth inhibition by hedgehog pathway blockade. Science 2002, 297:1559-1561.

43. Thompson MC, Fuller C, Hogg TL, Dalton J, Finkelstein D, Lau CC, Chintagumpala M, Adesina A, Ashley DM, Kellie SJ, Taylor MD, Curran T, Gajjar A, Gilbertson RJ: Genomics identifies medulloblastoma subgroups that are enriched for specific genetic alterations. J Clin Oncol 2006, 24:1924-1931.

44. Romer J, Curran T: Targeting medulloblastoma: small-molecule inhibitors of the Sonic Hedgehog pathway as potential cancer therapeutics. Cancer Res 2005, 65:4975-4878.

45. Sasai K, Romer JT, Lee Y, Finkelstein D, Fuller C, McKinnon PJ, Curran T: Shh pathway activity is down-regulated in cultured medulloblastoma cells: implications for preclinical studies. Cancer Res 2006, 66:4215-4222.

doi:10.1186/1477-7819-12-373

Cite this article as: Lin et al:: DJ-1 is activated in medulloblastoma and is associated with cell proliferation and differentiation. World Journal of Surgical Oncology 2014 12:373.

\section{Submit your next manuscript to BioMed Central and take full advantage of:}

- Convenient online submission

- Thorough peer review

- No space constraints or color figure charges

- Immediate publication on acceptance

- Inclusion in PubMed, CAS, Scopus and Google Scholar

- Research which is freely available for redistribution 